\title{
Helpful or harmful? Exploring the impact of social media usage on intimate relationships
}

\author{
Naomi Whiteside \\ RMIT University \\ naomi.whiteside@rmit.edu.au
}

\section{Torgeir Aleti}

RMIT University

Jason Pallant

Swinburne University

\section{John Zeleznikow}

Victoria University

\section{Abstract}

Internet access in Australia is increasing with the most popular online activity reported by Australians being social media use. The literature is divided as to whether social media use is helpful or harmful to intimate relationships. Recent research from an Australian family counselling provider indicates that social media use is resulting in negative intimate relationship outcomes, echoing recent American research findings. However, other researchers note that social media use can have positive outcomes for intimate relationships and individuals. These different findings prompted this research which focuses on the impact of social media usage on intimate relationships using Facebook as a case study. A survey of 518 Australians examining Facebook usage, relationship satisfaction and household income was undertaken. The results suggest that relationship satisfaction varies based on types of social media usage when controlled for household income. For most respondents, social media usage did not have a negative impact on their relationship. However, results indicated that where their partner was a 'friend' on social media, they were less likely to report concerns relating to social media usage impacting their relationship. It was also found that those living alone or with children on low incomes were more likely to be dissatisfied with their relationships and rely on social media to connect with others. Finally, four types of Facebook usage were identified and mapped against intensity of usage and relationship satisfaction, indicating that the way in which social media is used impacts relationship satisfaction. These findings indicate that social media use is helpful for some intimate relationships and harmful for others based on individual usage and their interaction with their partner via the platform.

Keywords: social media; social networking; intimate relationships; Facebook; relationship satisfaction.

\section{Introduction}

Internet usage has become a natural part of everyday life in Australia. In 2015, 86\% of all Australian households had an internet connection (ABS, 2016). One of the most popular activities online is social networking with $72 \%$ of Australians indicating that they used the internet at home for social networking (ABS, 2016). While there is hardly any difference in internet usage between women and men ( 84 and $85 \%$ respectively), individuals with a 
personal income below AU $\$ 40,000$, and those who had not completed secondary school, were less likely to use the internet (ABS, 2016).

Online social networking sites allows users to form, build and grow relationships in new ways. Some of the more popular social media sites are those classified as 'Social Community' sites (Tuten \& Solomon, 2015). Social community sites are those made for users to share, socialise and converse; typical examples are Facebook, Twitter and LinkedIn (Constantinides, 2014). Further, these social communities are used for different reasons. Users primarily turn to Facebook for relationships, LinkedIn to build a professional identity, while Twitter is more about conversations than relationships (Kietzmann, Hermkens, McCarthy, \& Silvestre, 2011). Since the focus in this research is on intimate relationships, Facebook was selected as the most suitable case for investigation.

Facebook is also the most used social media platform in Australia, with Sensis (2017) reporting that $94 \%$ of respondents indicated that they used the site. This figure is higher than American estimates which note that Facebook usage sits at $71 \%$ of online adults (Pew Research Center, 2016). 'Facebook, like other social media sites, is a platform where users can update their networks about how they are feeling by regularly posting status updates' (Carlson, Farrelly, Frazer, \& Borthwick, 2015, p5). Facebook is particularly useful in terms of enabling users to 'relate' to one another whereby 'two or more users have some form of association that leads them to converse, share objects of sociality, meet up, or simply just list each other as a friend...' (Kietzmann et al., 2011, p. 246).

As mobile device ownership increases, so does the frequency of access to social media sites, with $35 \%$ of users reporting visiting a social media site more than five times a day (Sensis, 2017). The average Australian now spends almost half a day per week (10 hours) on Facebook alone (Sensis, 2017). Social media is accessed anytime and anywhere, with $57 \%$ reporting checking in first thing in the morning, $84 \%$ using it in their living room, and $12 \%$ using it in the toilet (Sensis, 2017).

A study carried out by a leading relationship support and counselling provider in Australia found that social media was increasingly having a negative impact on intimate relationships (Relationships Australia, 2011). Some research indicates that social networking sites are being used for interpersonal electronic surveillance (IES) (R S Tokunaga, 2010) or partner surveillance (Fox \& Warber, 2014). Recent American research indicates that social media usage is contributing to negative relationship outcomes such as divorce (Baker \& Oswald, 2010; Clayton, Nagurney, \& Smith, 2013). In addition, US legal practitioners report that social media content is increasingly being used as evidence in divorce proceedings (AAML, 2010). From this perspective, it appears that an increased intensity of social media usage is linked to dissatisfaction with intimate relationships. However, other studies have suggested an opposite effect as social media allows users '...to share personal information, build and maintain social relationships, and have fun' (Hu, Kettinger, \& Poston, 2015 p. 391).

Caers et al. (2013) point out that while many studies examine Facebook usage, the changing nature of the platform and the diversity and limitations of the samples studied to date indicates a need for on-going research into the topic. Ellison, Steinfield, and Lampe (2007 p. 631) note that there is potential for individuals to overuse social media and consequently '...the impact of such extreme usage patterns on individuals and their romantic relationships needs further exploration'. Papp, Danielewicz, and Cayemberg (2012) also highlight the need for further research into how technology use impacts intimate relationships. 
This research seeks to explore the impact that social media use has on intimate relationships in the Australian context with a specific focus on understanding the experience of low income respondents. The paper is structured as follows: A background to the study is presented that highlights recent relevant research relating to social media and relationships. This is followed by a discussion of the methodology and results. The paper concludes with a summary of the research and a discussion of potential future work.

\section{Background}

Since the launch of Facebook in 2004 social media has inspired numerous studies into the impact that usage of platforms has on the lives and relationships of users (Boyd \& Ellison, 2007). Social media use has been found to have both negative (Clayton, Nagurney, et al., 2013; Clayton, Osborne, Miller, \& Oberle, 2013; Mod, 2010; Muise, Christofides, \& Desmarais, 2009; Rahaman, 2015) and positive impacts on users' relations to others (Baker \& Oswald, 2010; N B Ellison et al., 2007). In contrast, a recent American study found that internet use had no impact on relationships for more than $60 \%$ of respondents (Pew Research Center, 2014). These and other studies are explored here.

\subsection{Peer group identification}

In the context of Facebook, a 'friend' is an individual, group or organisation that users have a connection with via the social media platform. Users may communicate and interact with friends in the social media environment. This is quite different from the commonly accepted notion that 'friends are individuals who have a close, personal relationship with one another that is characterized by mutual positive feelings' (Erdley, Nangle, \& Burns, 2011 p. 669). Indeed Gilbert and Karahalios (2009 p. 211) note that 'social media treats all users the same: trusted friend or total stranger, with little or nothing in between'. However, individuals generally have a range of friendships that are characterized by varying degrees of closeness, self-disclosure and reciprocity (Gilbert \& Karahalios, 2009).

The friendship spectrum can be characterized in terms of tie-strength (Granovetter, $1973 \mathrm{p}$. 1361), the 'combination of the amount of time, the emotional intensity, the intimacy (mutual confiding), and the reciprocal services which characterize the tie'. Weak ties can be considered acquaintances that you do not know well whereas strong ties are trusted friends that you are closely involved with (Gilbert \& Karahalios, 2009; Hacker, Wickramasinghe, \& Durst, 2017).

In the context of this research 'friend' means a social media friend who may sit anywhere on the spectrum of tie-strength. To narrow this range, we adopted peer group, '... a group of individuals who are approximately the same age, formed from common interests and affective bonds' (Hamit, 2011 p. 1073), to indicate social media friends that are more than just weak ties. This is in line with the use of the term peer in the context of social media users by Wang, Yu, and Wei (2012), who created a peer group identification scale (see appendix one) used in this research.

Valenzuela et al. (2010), indicate that social media provides an avenue of social support whereby individuals who are experiencing difficulties in their offline relationship can find solace online via social media friends. While Carlson et al. (2015, pp. 6-7) note that social media '...offers a platform where users could receive support and encouragement through interactions with friends and family'. This is supported by Song et al.'s (2014) research into a 'social augmentation hypothesis' or a 'social compensation hypothesis' which posits that 
people seek company and support online when their offline network is limited (Berger, 1986 pp. 48-49; Song et al., 2014 p. 447). As Tokunaga (2011 p. 425) notes, social networking sites have unique affordances '...that support the maintenance of existing relationships and formation of new social ties'. Social media also provides 'utilitarian benefits' as it allows users to keep up to date with the activities and preferences of friends or connections (Hu et al., 2015 p. 394). As such, when social media is used to connect with friends and family, it may have a positive impact on relationships.

Social capital can be described as 'the benefits individuals derive from their social relationships and interactions: resources such as emotional support, exposure to diverse ideas, and access to non-redundant information' (Nicole B. Ellison, Steinfield, \& Lampe, 2011 p. 873). Indeed, social media use can provide positive benefits for users, including increased social capital (N. Ellison, Steinfield, \& Lampe, 2006; N B Ellison et al., 2007; Nicole B. Ellison et al., 2011; Lambert, 2016). In addition, Baker and Oswald (2010) found that using social media increased perceptions of friendship quality and provided social support for people who were shy.

\subsection{Facebook intensity: Beyond frequency and duration of social media use}

Facebook intrusion can be characterised as the usage of Facebook that interferes with daily life and personal relationships (N B Ellison et al., 2007). This intrusion has been characterised by Turel and Serenko (2012, p. 514) as 'social networking website addiction' which Turel (2015) notes may lead users to experience feelings of guilt. Ellison et al. (2007 p. 631) contend that Facebook intrusion, '...may be associated with relationship dissatisfaction'. This position is reflected in the work of Muise, Christofides, and Desmarais (2009 p. 443) whose research showed that there was '...a significant association between time spent on Facebook and jealousy-related feelings and behaviours experienced on Facebook'. Recent research in Australia also highlights that the heavy use of social media (defined in the study as accessing it five or more times a day), can increase the likelihood of 'FOMO'; the Fear Of Missing Out (APS, 2015). FOMO is indicated where individuals feel anxious when disconnected from social media and experience increased concern about missing out on social interaction with peers as a result (APS, 2015).

A Swedish study (Denti et al., 2012 p. 26) reported that ... 'those who used Facebook more [in this instance women with low incomes and education levels] rated themselves as feeling less happy and content with their lives'. This resonates with the work from Chou and Edge (2012) who found that students with higher levels of Facebook usage were more likely to perceive that others had happier lives. Maier, Laumer, Eckhardt, and Weitzel (2015, pp. 447-448) note that social media users may experience 'social overload': feeling exhausted by requests for social support from friends in their online social networks. Thus, people may use social media differently, and that socio-economic status could play an important role in to what extent Facebook functions as a positive or negative influence on relationships.

While the aforementioned research focuses on frequency and duration of use, Ellison et al. (2007 p. 1150) created the 'Facebook Intensity' scale (see appendix one) to provide a 'better measure of Facebook use than frequency and duration indices'. Facebook intensity encompasses frequency and duration of use, but also an individual's feelings about using Facebook as well as their number of 'friends'. When intensity is seen in this way, it includes the size of an individual's network, frequency of use as well as the sentiments towards the site. As such, intensity is likely to impact relationship satisfaction. Ellison et al. (2007 p. 1162) found 
'that certain kinds of Facebook use (articulated by [the] Facebook intensity items) can help students accumulate and maintain bridging social capital'.

\subsection{Relationship satisfaction}

Some studies point to social media use playing a role in relationship problems (AAML, 2010; Clayton, Nagurney, et al., 2013; Pew Research Center, 2014; Relationships Australia, 2011; Relationships Australia Victoria, 2012; Valenzuela, Halpern, \& Katz, 2014). A Pew Research (2014) study found that almost one third of respondents felt that social media had an impact on their relationship. Uncertainty Reduction Theory (URT), may help to explain these relationships.

Developed by Berger and Calabrese (1975), URT 'argues that relationships develop when participants are able to reduce uncertainty about each other and disintegrate when participants are unable to reduce uncertainty about each other' (Parks \& Adelman, 1983 p. 57). While the initial theory focused on the early stages of relationship development, over time the theory has been applied to '...the entire relational life cycle' (Parks \& Adelman, 1983 p. 56). Parks and Adelman (1983 p. 56) extended URT, examining the theory and its linkages to relationship stability. Specifically, they posit that increasing the 'amount of communication with a partner's network' will reduce uncertainty and enhance the stability of a relationship (Parks \& Adelman, 1983 p. 57). URT was used by Rahaman (2015) in exploring the impact of Facebook use on relationships and it is used in this study as a theoretical lens to support the analysis and interpretation of results (Stewart \& Klein, 2016). We propose that social media provides another channel via which partners can engage with one another and their extended group of family and friends. As such, social media has the potential to increase connections and information sharing with a partner's network, reducing uncertainty in a relationship and potentially enhancing relationship satisfaction. For the purposes of this study relationship satisfaction is measured using the Relationship Assessment Scale (RAS) developed by Hendrick et al. (1988) (see appendix one).

Social media use could have an impact on relationship satisfaction for some couples. A recent study noted that those with a household income lower than $\$ 30,000$ USD were likely to argue about the time their partner spent online, or to find '...the online activity of their partner upsetting' (Pew Research Center, 2014 p. 16). Use of social media can cause conflict and drive dissatisfaction with relationships, as the platform provides a means for partners to meet others, leading to potential infidelity (McDaniel, Drouin, \& Cravens, 2017). Dang-Pham, Pittayachawan, and Nkhoma (2015) point out that stalking and harassment are among the negative behaviours enabled by such social networking services. Therefore, we propose that what people do and who they do it with on social media, is just as important as the intensity of use and peer connections when exploring the ramifications in terms of relationship satisfaction. We also posit that the impact of social media usage on a relationship is influenced by the way in which a partner uses (or doesn't use) social media. For instance, overuse may not be considered problematic if both partners use social media to a similar degree and for similar things.

Based on existing literature, we propose that there are multiple types of social media users. These types differ in the reasons for each individual's usage of social media, their intensity of usage, and the dynamics of usage relative to their relationship partner. That is, an individual's reasons for use, intensity of use, and usage relative to their partner, distinguishes between types of users. We propose that membership in these user groups is dependent on a range of 
individual characteristics, including gender, age, marital status, location, education, socioeconomic status, and peer group identification. For example, we predict that some types of users will be more likely male than female, and so on. Finally, we propose that relationship satisfaction will differ across different types of users. Based on these propositions, the conceptual model displayed in Figure 1 is proposed.

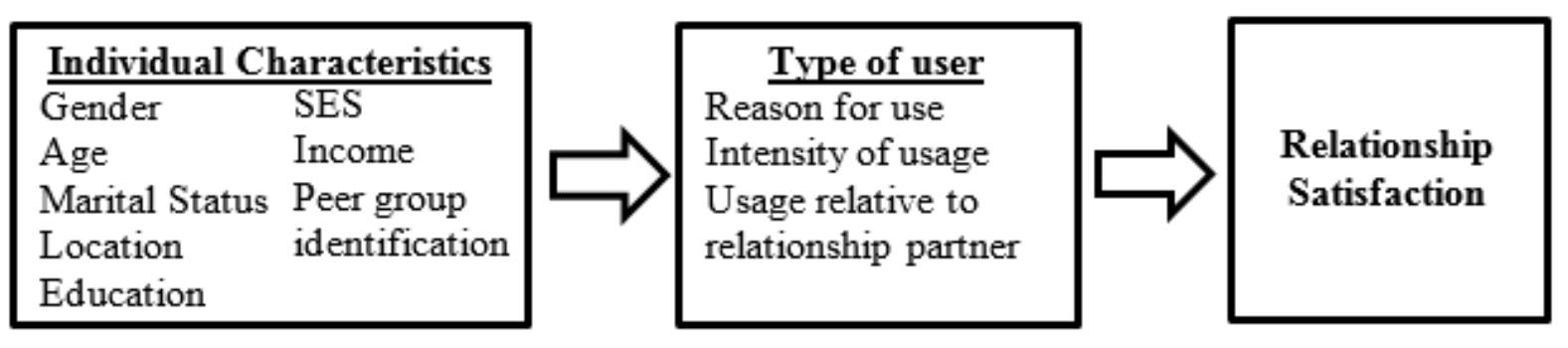

Figure 1. Conceptual Model.

Based on this conceptual model, this study seeks to address three key research questions. Firstly, the literature reviewed above indicate that income and education in particular were related to how people use social media. In particular, Denati et al. (2012) suggested that low income and education could be related to higher intensity of usage - with negative implications on wellbeing. The intensified online relationships, may in turn reflect satisfaction with intimate relationships. As such, we propose the following research question:

Research question 1: Are there any differences in relationship satisfaction, Facebook intensity and identification with peer groups on social media when it comes to household income and living arrangements?

Secondly, we wanted to further investigate the relationship between how people use Facebook and their relationship satisfaction. Previous research has suggested that Facebook usage can have positive as well as negative impacts on relationship satisfaction. Further, as suggested by Pew Research (2014), those on a lower income were more likely to find the online activities of their partners upsetting. This leads us to the second research question:

Research question 2: Controlling for household income, does the way people use Facebook influence relationship satisfaction?

Finally, we wanted to investigate to what extent people with different characteristics and usage patterns could be described as particular groups of Facebook users. URT suggests that people differ in their ability to reduce uncertainty about each other in relationships. It is possible that this ability can be enhanced or reduced based on how and why people use social media such as Facebook. The literature reviewed here suggest that usage patterns and personal characteristics may impact relationship satisfaction, but it is unclear what patters and characteristics are most salient. This leads us to our final research question:

Research question 3: Based on intensity of Facebook usage, reasons for usage and online relations with partner, a); what groups of user types exist, b); what factors predict membership in these groups, and c); do these groups differ based on relationship satisfaction?

\section{Methodology}

A survey was used to examine the impact Facebook usage has on intimate relationships. Specifically, this study sought to explore the way in which Facebook was used and if specific 
usage impacted intimate relationships. The survey was distributed through a reputable Australian market research company (the Online Research Unit, http://www.theoru.com/). 518 responses were elicited from their panel. Four respondent screening criteria were used; participants had to be above 18 years of age, currently in a relationship, current users of Facebook and $40 \%$ of the sample had to belong to a low-income category. An Australian government standard for determining access to services and support was used to identify respondents on low income (DHS, 2015). The relationship between patterns of Facebook usage and key demographics was also examined. Demographics relating to relationship and marital status, age, education and income were used.

The survey instrument consisted of three existing validated scales developed to examine aspects of relationship satisfaction and Facebook use. The 'Facebook Intensity' scale (N B Ellison et al., 2007) was developed to examine the degree of Facebook usage via measures encompassing emotional connection and integration into daily routines in addition to frequency and duration of use. This widely used scale was adopted to quantify intensity of Facebook use in this study.

Wang et al. (2012) developed and validated the 'Identification with Peer Group Online' scale to investigate the influence of peer group identification and communication on purchase intention. This scale was adopted for the study to investigate the influence of peer group identification on relationship satisfaction.

The widely used 'Relationship Assessment Scale' is a seven-item generic measure of relationship satisfaction developed and validated by Hendrick (1988) and Hendrick, Dicke, \& Hendrick (1998), which was used to quantify relationship satisfaction. All three scales are presented in appendix one.

The survey also included a set of questions about reasons for using Facebook. These questions were based on the Sensis (2016 p.35) report 'Reasons for using social networking sites', and were adapted to suit this particular study. Finally, the survey asked about the frequency of Facebook usage compared with a partner, whether the participants included or excluded their partner (as a friend) on Facebook, and whether their partner was part of the peer group that they would normally interact with on Facebook (see appendix one). This was of particular interest as it facilitated examination of a connection with a partner's network via Facebook, supporting analysis with respect to extended Uncertainty Reduction Theory (URT) (Parks \& Adelman, 1983).

The relationships between variables were explored using analysis of variance (ANOVA), regression analysis, and Latent Class Analysis (LCA). We use LCA to categorise patterns of Facebook usage. We then tested different factors that influence which type of user each individual is. Finally, the groups identified by this model were then compared with respect to levels of relationship satisfaction using ANOVA and post-hoc tests. The results were analysed using the extended URT as a lens.

\section{Results}

The demographic profile of respondents is displayed in Table 1. The sample included equal proportions of males and females from a range of age groups, educations, locations and marital statuses. 


\begin{tabular}{|c|c|c|c|}
\hline \multicolumn{2}{|r|}{ Variable } & \multirow{2}{*}{$\begin{array}{r}N \\
255\end{array}$} & \multirow{2}{*}{$\begin{array}{r}\text { Percent } \\
49.2 \%\end{array}$} \\
\hline Gender & Male & & \\
\hline & Female & 263 & $50.8 \%$ \\
\hline \multirow[t]{5}{*}{ Age } & $18-29$ & 55 & $10.6 \%$ \\
\hline & $30-39$ & 128 & $24.7 \%$ \\
\hline & $40-49$ & 110 & $21.2 \%$ \\
\hline & $50-64$ & 129 & $24.9 \%$ \\
\hline & $65-$ & 96 & $18.5 \%$ \\
\hline \multirow[t]{4}{*}{ Marital status } & Never married & 34 & $6.6 \%$ \\
\hline & Defacto & 68 & $13.1 \%$ \\
\hline & Married & 402 & $77.6 \%$ \\
\hline & Separated / Divorced / Widowed & 14 & $2.7 \%$ \\
\hline \multirow[t]{2}{*}{ Habitat } & Metropolitan & 393 & $75.9 \%$ \\
\hline & Rural / Remote & 125 & $24.1 \%$ \\
\hline \multirow[t]{4}{*}{ Education } & Primary school or Some high school & 62 & $12.0 \%$ \\
\hline & Completed high school & 76 & $14.7 \%$ \\
\hline & TAFE Certificate & 147 & $28.4 \%$ \\
\hline & Tertiary & 233 & $45.0 \%$ \\
\hline \multirow[t]{6}{*}{ Personal Income } & Under $\$ 20,000$ & 125 & $24.1 \%$ \\
\hline & $\$ 20,001-\$ 40,000$ & 93 & $18.0 \%$ \\
\hline & $\$ 40,001-\$ 60,000$ & 103 & $19.9 \%$ \\
\hline & $\$ 60,001-\$ 80,000$ & 84 & $16.2 \%$ \\
\hline & $\$ 80,000-\$ 100,000$ & 55 & $10.6 \%$ \\
\hline & Over $\$ 100,000$ & 58 & $11.2 \%$ \\
\hline \multirow{4}{*}{$\begin{array}{l}\text { Household } \\
\text { income } \\
\text { (all figures in } \\
\text { AUD) }\end{array}$} & Live alone, income $<\$ 30,000$ & 18 & $3.5 \%$ \\
\hline & Live with a partner, income $<\$ 45,000$ & 142 & $27.4 \%$ \\
\hline & Live with children, income $<\$ 60,000$ & 48 & $9.3 \%$ \\
\hline & Income $>\$ 60,001$ & 310 & $59.8 \%$ \\
\hline
\end{tabular}

Table 1. Sample profile.

\section{RQ 1: Household income, Facebook and relationship satisfaction}

The first research question investigated differences in relationship satisfaction, Facebook intensity and identification with peer groups on social media when it comes to household income and living arrangements. To investigate this question, an ANOVA analysis was conducted. The results are reported on Table 2. 


\begin{tabular}{|c|c|c|c|c|c|}
\hline & Variable & $N$ & Mean & $F$ & Sig. \\
\hline \multirow{4}{*}{$\begin{array}{l}\text { Relationship } \\
\text { satisfaction }\end{array}$} & Live alone, income $<\$ 30,000$ & 18 & 3.85 & \multirow{4}{*}{4.12} & \multirow{4}{*}{.007} \\
\hline & Live with a partner, income $<\$ 45,000$ & 142 & 4.17 & & \\
\hline & Live with children, income $<\$ 60,000$ & 48 & 3.83 & & \\
\hline & Income $>\$ 60,001$ & 310 & 4.22 & & \\
\hline \multirow[t]{4}{*}{ Facebook intensity } & Live alone, income $<\$ 30,000$ & 18 & 3.12 & \multirow{4}{*}{2.26} & \multirow{4}{*}{.081} \\
\hline & Live with a partner, income $<\$ 45,000$ & 142 & 2.69 & & \\
\hline & Live with children, income $<\$ 60,000$ & 48 & 3.04 & & \\
\hline & Income $>\$ 60,001$ & 310 & 2.83 & & \\
\hline Identification with & Live alone, income $<\$ 30,000$ & 18 & 2.99 & \multirow{4}{*}{3.18} & \multirow{4}{*}{.024} \\
\hline \multirow[t]{3}{*}{ Peer Group } & Live with a partner, income $<\$ 45,000$ & 142 & 2.58 & & \\
\hline & Live with children, income $<\$ 60,000$ & 48 & 3.01 & & \\
\hline & Income $>\$ 60,001$ & 310 & 2.78 & & \\
\hline
\end{tabular}

Table 2. ANOVA: household income.

The results indicate significant differences for relationship satisfaction $[\mathrm{F}(3,514)=4.12, \mathrm{p}<0.01]$ and identification with peer group $[\mathrm{F}(3,514)=3.18, \mathrm{p}<0.05]$ across the income groups. Interestingly, relationship satisfaction is at a similar level to the high-income group for couples living together on less than $\$ 45,000$ per year. However, the level of satisfaction drops for those living alone (on less than $\$ 30,000$ ) and those living with dependent children on less than $\$ 60,000$. These relationships appear opposite when it comes to Facebook intensity (not significant) and identification with peers on Facebook. Thus, those living alone or with children on low income are less satisfied with their relationships and may rely more on Facebook to connect with others.

\section{$R Q$ 2: Ways of using Facebook, household income and relationship satisfaction}

The second research question addressed how the differences in the ways that people use Facebook influenced relationship satisfaction while also controlling for household income. To address this question, we split the relationship satisfaction variable into two categories; unsatisfied and satisfied. Based on the seven-point scale measuring satisfaction, participants who answered three or below on most the questions were regarded as unsatisfied. This led to $136(26.3 \%)$ unsatisfied participants, and 382 (73.7\%) satisfied participants. Further, we combined the first three categories of household income investigated in RQ1 as low income $(40.2 \%)$, and compared this category with the high-income category $(59.8 \%)$. From this, we compared the percentage of satisfied and unsatisfied participants based on reasons for using Facebook and compared these results for low and high income groups. Table 3 presents the results of this analysis.

The most interesting results are those which deviate by more than $10 \%$ from the overall level of unsatisfied (26.3\%) and satisfied (73.7\%) participants (highlighted). In low-income households only, participants seemed less satisfied with their relationship when the partner is a heavier Facebook user then them; 39.0\% of low household income participants with heavy Facebook using partners were unsatisfied with their relationships.

Another key difference in relationship satisfaction was found based on whether respondents used Facebook to keep in touch with family and friends. In the low-income category $47.7 \%$ of respondents who did not use Facebook in this way were dissatisfied with their relationships. 
A similar trend was also observed in the high-income category with $40.0 \%$ dissatisfied when Facebook was not used to keep in touch with family and friends.

\begin{tabular}{llllll}
\hline \multirow{2}{*}{ Variable } & & \multicolumn{2}{c}{ Low income household } & \multicolumn{2}{c}{ High income household } \\
& & Unsatisfied & Satisfied & Unsatisfied & Satisfied \\
\hline Partner FB usage & More & $39.0 \%$ & $61.0 \%$ & $29.5 \%$ & $70.5 \%$ \\
& Same & $27.9 \%$ & $72.1 \%$ & $20.2 \%$ & $79.8 \%$ \\
& Less & $26.4 \%$ & $73.6 \%$ & $21.7 \%$ & $78.3 \%$ \\
\hline Partner part of FB peer & No & $30.2 \%$ & $69.8 \%$ & $26.6 \%$ & $73.4 \%$ \\
group & Yes & $30.4 \%$ & $69.6 \%$ & $20.4 \%$ & $79.6 \%$ \\
\hline Partner friend on FB & No & $29.1 \%$ & $70.9 \%$ & $25.0 \%$ & $75.0 \%$ \\
& Yes & $31.0 \%$ & $69.0 \%$ & $22.9 \%$ & $77.1 \%$ \\
\hline Keep in touch with fam. \& & No & $47.7 \%$ & $52.3 \%$ & $40.0 \%$ & $60.0 \%$ \\
friends & Yes & $25.6 \%$ & $74.4 \%$ & $21.8 \%$ & $78.2 \%$ \\
\hline For work & No & $27.6 \%$ & $72.4 \%$ & $23.1 \%$ & $76.9 \%$ \\
& Yes & $62.5 \%$ & $37.5 \%$ & $29.2 \%$ & $70.8 \%$ \\
\hline To connect with & No & $26.4 \%$ & $73.6 \%$ & $21.9 \%$ & $78.1 \%$ \\
organisations & Yes & $57.7 \%$ & $42.3 \%$ & $32.0 \%$ & $68.0 \%$ \\
\hline To gather information & No & $30.0 \%$ & $70.0 \%$ & $23.2 \%$ & $76.8 \%$ \\
& Yes & $31.6 \%$ & $68.4 \%$ & $24.7 \%$ & $75.3 \%$ \\
\hline To share information & No & $30.6 \%$ & $69.4 \%$ & $24.0 \%$ & $76.0 \%$ \\
\hline To meet new people & Yes & $28.6 \%$ & $71.4 \%$ & $21.9 \%$ & $78.1 \%$ \\
\hline
\end{tabular}

Table 3. Differences in Facebook usage based on household income and relationship satisfaction.

Low income respondents who used Facebook for different reasons than keeping in touch with family and friends were more likely to be unsatisfied with their relationships. $62.5 \%$ of those who used Facebook for work, and 57.7\% of those who use Facebook to connect with organisations were dissatisfied with their relationship. That is, some low-income participants may seek to 'escape' though social media, which relates to higher dissatisfaction with their relationships.

To further investigate the relationships between ways of using Facebook and relationship satisfaction, we conducted a regression analysis with relationship satisfaction as the dependent variable (DV), and household income and the Facebook usage variables as independent variables (IV). The results are shown in Table 4.

The model explains about $8 \%$ of the variation in relationship satisfaction $\left(\mathrm{R}^{2}=.078\right)$. Considering the vast number of variables that would affect a person's relationship satisfaction, it is surprising to find any relationships here at all. However, the model shows statistically significant relationships. Keeping in touch with friends and family is positively related to satisfaction, while using Facebook to connect with organisations is negatively related to relationship satisfaction. Excluding the partner from the peer group on Facebook was negatively associated with relationship satisfaction and those with partners that were heavy Facebook users were less satisfied with their relationships. Finally, living alone with children on a low income also negatively affects relationship satisfaction. The regression largely supports the variations in relationship satisfaction uncovered in Table 4. 


\begin{tabular}{llll}
\hline Item & Std. $\boldsymbol{\beta}$ & $T$ & Sig. \\
\hline (Constant) & & 18.177 & .000 \\
Partner more FB use & -.107 & -1.991 & .047 \\
Partner same FB use & -.030 & -.602 & .548 \\
Partner part of FB peer group & -.109 & -2.078 & .038 \\
Partner friend on FB & -.087 & -1.620 & .106 \\
Keep in touch with fam. \& friends & .108 & 2.308 & .021 \\
For work & .027 & .579 & .563 \\
To connect with organisations & -.129 & -2.746 & .006 \\
To gather information & .001 & .017 & .986 \\
To share information & .013 & .265 & .791 \\
To meet new people & .023 & .502 & .616 \\
Facebook intensity & -.091 & -1.269 & .205 \\
Identification with Peer Group & -.008 & -.110 & .913 \\
Live alone, income $<\$ 30,000$ & -.069 & -1.589 & .113 \\
Live with a partner, income $<\$ 45,000$ & -.021 & -.469 & .639 \\
Live with children, income $<\$ 60,000$ & -.103 & -2.256 & .025 \\
\hline
\end{tabular}

Table 4. Regression analysis of relationship satisfaction and Facebook usage.

\section{RQ 3: Different types of Facebook users}

The third research question related to whether different groups of Facebook users could be identified based on the variables of Facebook usage and the intensity of use, what factors may predict membership in these groups, and whether these groups differ based on relationship satisfaction. We tested this question through a Latent Cluster Analysis (LCA). The convergence criterion was set at 0.000001 (Collins \& Lanza, 2010) and 50 random sets of starting parameters were used (Masyn, 2013) to reduce the likelihood of convergence to a local maxima (McCutcheon, 2002). The variables in this LCA were the same as in Table 3, with the addition of the average score on the Facebook Intensity scale.

The Bayesian Information Criterion (BIC) was used to compare relative model fit (Collins \& Lanza, 2010; Masyn, 2013). The 4-cluster solution resulted in the lowest BIC value, suggesting this solution provided the best relative model fit (Collins \& Lanza, 2010; Masyn, 2013). Finally, the segment profiles were considered to examine over-extraction (Masyn, 2013), class separation (Collins \& Lanza, 2010) and interpretability of the results (Wedel \& Kamakura, 2000). The 4-cluster solution displayed no evidence of over-extraction, as the smallest cluster was $10 \%$. Additionally, these clusters led to meaningful interpretation as the clusters showed strong class separation. Table 5 displays the profile of the developed clusters in the chosen 4cluster solution.

Cluster $1(39 \%)$ use Facebook only to keep in touch with family and friends and most of this cluster has their partner as a friend on Facebook (91\%). They are also relatively intense users of Facebook with the second highest Facebook intensity score. As such, this cluster is given the label Connectors. The second cluster $(29 \%)$ also primarily use Facebook to keep in touch with family and friends (80\%). However, in contrast to Cluster 1, most respondents in Cluster 2 do not have their partner as a friend on Facebook (90\%). In addition, they have the lowest intensity of use in the sample, and their partners are likely to be even lighter users than them (possibly non-users). This cluster is therefore labelled Light Users. Cluster 3 (22\%), display the highest intensity of Facebook usage (Mean $=3.65$ ), and are the only cluster where most respondents use Facebook to gather (60\%) and share information (65\%). Based on this profile, the third cluster is labelled Heavy Users. Finally, Cluster $4(10 \%)$ describes a category of 
Disconnectors, as most of this cluster do not use Facebook for any of the listed tasks. Although they have an account, their intensity of use remains low. Additionally, this cluster was the most likely to state that their partner uses Facebook more than them $(88 \%)$, which further verifies the conscious disconnect from Facebook.

\begin{tabular}{|c|c|c|c|c|c|}
\hline & & $\begin{array}{c}\text { Cluster } 1 \\
\text { (Connectors) }\end{array}$ & $\begin{array}{c}\text { Cluster } 2 \\
\text { (Light Users) }\end{array}$ & $\begin{array}{c}\text { Cluster } 3 \\
\text { (Heavy Users) }\end{array}$ & $\begin{array}{c}\text { Cluster } 4 \\
\text { (Disconnectors) }\end{array}$ \\
\hline Cluster Size & $\%$ & 39 & 29 & 22 & 10 \\
\hline \multirow{2}{*}{$\begin{array}{l}\text { Keep in touch with } \\
\text { fam. \& friends }\end{array}$} & $\%$ No & 00 & 20 & 09 & 68 \\
\hline & $\%$ Yes & 100 & 80 & 91 & 32 \\
\hline \multirow[t]{2}{*}{ For work } & $\% \mathrm{No}$ & 100 & 98 & 82 & 67 \\
\hline & $\%$ Yes & 00 & 02 & 18 & 33 \\
\hline \multirow{2}{*}{$\begin{array}{l}\text { To connect with } \\
\text { organisations }\end{array}$} & $\%$ No & 99 & 93 & 54 & 80 \\
\hline & $\%$ Yes & 01 & 07 & 46 & 21 \\
\hline \multirow[t]{2}{*}{ To gather information } & $\%$ No & 92 & 88 & 40 & 76 \\
\hline & $\%$ Yes & 08 & 12 & 60 & 24 \\
\hline \multirow[t]{2}{*}{ To share information } & $\%$ No & 95 & 93 & 35 & 92 \\
\hline & $\%$ Yes & 05 & 07 & 65 & 08 \\
\hline \multirow[t]{2}{*}{ To meet new people } & $\%$ No & 100 & 99 & 76 & 95 \\
\hline & $\%$ Yes & 00 & 01 & 24 & 05 \\
\hline \multirow[t]{3}{*}{ Partner FB usage } & \%More & 38 & 04 & 16 & 88 \\
\hline & \%Same & 35 & 11 & 30 & 11 \\
\hline & \%Less & 27 & 85 & 54 & 01 \\
\hline \multirow{2}{*}{$\begin{array}{l}\text { Partner part of FB peer } \\
\text { group }\end{array}$} & $\%$ Yes & 69 & 02 & 62 & 59 \\
\hline & $\% \mathrm{No}$ & 31 & 98 & 38 & 41 \\
\hline \multirow[t]{2}{*}{ Partner friend on FB } & $\%$ Yes & 91 & 10 & 86 & 94 \\
\hline & $\% \mathrm{No}$ & 09 & 90 & 14 & 06 \\
\hline Facebook intensity & Mean & 2.78 & 2.37 & 3.65 & 2.44 \\
\hline
\end{tabular}

Table 5. Cluster profiles based on preferred 4-cluster solution

The next step of our analysis included investigating the factors predicting 'cluster membership'. This was achieved by including demographic data as well as strength of peer group identification on social media as covariates in the LCA. The results of this covariate analysis are displayed in Table 6. 


\begin{tabular}{|c|c|c|c|c|c|c|}
\hline Covariates & Connectors & $\begin{array}{l}\text { Light } \\
\text { Users }\end{array}$ & $\begin{array}{l}\text { Heavy } \\
\text { Users }\end{array}$ & Disconnectors & Wald & $p$-value \\
\hline Male & 0.31 & -0.76 & 0.37 & 0.08 & \multirow{2}{*}{12.79} & \multirow{2}{*}{0.01} \\
\hline Female & -0.31 & 0.76 & -0.37 & -0.08 & & \\
\hline Age & 0.00 & 0.06 & -0.01 & -0.05 & 12.63 & 0.01 \\
\hline Never married & 0.22 & 0.25 & -0.61 & 0.14 & \multirow{4}{*}{5.36} & \multirow{4}{*}{0.80} \\
\hline Defacto & 0.19 & -0.05 & 0.34 & -0.47 & & \\
\hline Married & -0.36 & -0.05 & -0.43 & 0.84 & & \\
\hline $\begin{array}{l}\text { Separated/Divorced/ } \\
\text { Widowed }\end{array}$ & -0.05 & -0.15 & 0.69 & -0.50 & & \\
\hline Metropolitan & -0.03 & -0.15 & 0.12 & 0.06 & \multirow{2}{*}{1.44} & \multirow{2}{*}{0.70} \\
\hline Rural/Remote & 0.03 & 0.15 & -0.12 & -0.06 & & \\
\hline Primary school or less & 2.01 & 0.91 & -2.09 & -0.84 & & \\
\hline Some high school & -0.27 & 0.15 & -0.17 & 0.29 & \multirow{4}{*}{17.94} & \multirow{5}{*}{0.12} \\
\hline Completed high school & -0.37 & -0.01 & 0.47 & -0.09 & & \\
\hline TAFE Certificate & -0.99 & -0.46 & 0.89 & 0.56 & & \\
\hline Tertiary & -0.38 & -0.59 & 0.90 & 0.08 & & \\
\hline Live alone, income $<\$ 30,000$ & -0.90 & 0.66 & -0.41 & 0.65 & \multirow{4}{*}{12.53} & \\
\hline $\begin{array}{l}\text { Live with a partner, income } \\
<\$ 45,000\end{array}$ & 0.40 & -0.55 & -0.08 & 0.23 & & \multirow{3}{*}{0.18} \\
\hline $\begin{array}{l}\text { Live with children, income } \\
<\$ 60,000\end{array}$ & -0.72 & -0.31 & -0.36 & 1.39 & & \\
\hline Income $>\$ 60,001$ & 1.22 & 0.21 & 0.85 & -2.27 & & \\
\hline Under $\$ 20,000$ & 1.48 & 0.42 & 1.95 & -3.85 & \multirow{6}{*}{13.66} & \multirow{6}{*}{0.55} \\
\hline$\$ 20,001-\$ 40,000$ & 0.46 & 0.51 & 0.04 & -1.00 & & \\
\hline$\$ 40,001-\$ 60,000$ & 0.15 & -0.07 & -0.21 & 0.13 & & \\
\hline$\$ 60,001-\$ 80,000$ & -0.48 & -0.44 & -0.42 & 1.34 & & \\
\hline$\$ 80,000-\$ 100,000$ & -0.64 & 0.01 & -0.61 & 1.24 & & \\
\hline Over $\$ 100,000$ & -0.97 & -0.42 & -0.74 & 2.13 & & \\
\hline Peer group identification & 0.50 & -0.81 & 1.54 & -1.24 & 37.52 & 0.00 \\
\hline
\end{tabular}

Table 6. Results of covariate analysis based on preferred 4-cluster solution.

This covariate analysis displayed significant results for gender (Wald $=12.79, \mathrm{p}<0.05$ ), age $($ Wald $=12.63, \mathrm{p}<0.05)$, and peer group identification $($ Wald $=37.52, \mathrm{p}<0.01)$. No differences were found regarding household income, marital status, location, education and income. This means that neither of these variables influences cluster membership in this analysis. For the variables with significant main effects, the specific coefficients were considered. A positive coefficient suggests that covariate increases the probability of membership in a cluster, while a negative coefficient implies the opposite. For gender, there was a positive impact on membership in the Connectors (0.31), Heavy Users (0.37) or Disconnectors (0.08) clusters for males, and a large negative impact on membership in the Light Users cluster (-0.76). That is, the light users are most likely women. In terms of age, increased age led to a higher probability of membership in the Light Users cluster (0.06) and lower likelihood of membership in the Disconnectors cluster (-0.05). Finally, peer identification had a positive impact on membership in either the Heavy Users (1.54) or Connectors (0.50) clusters, but a negative impact on the Disconnectors (-1.24) and Light Users (-0.81) clusters. This means that the heavy users and the connectors feel more connected to their peers on Facebook than the light users and disconnectors. 
With the developed clusters profiled and labelled, they were compared in terms of relationship satisfaction. This was achieved through a one-way ANOVA where the DV was the average score on the relationship satisfaction scale, and the IV was cluster membership. Tukey's posthoc tests were used to compare differences between individual clusters. The results of this ANOVA analysis are displayed in Table 7.

\begin{tabular}{lcccc}
\hline \multicolumn{1}{c}{ Cluster } & N & Mean & F & Sig. \\
\hline Connectors & 217 & 4.29 & & \\
Light Users & 145 & 4.06 & & \\
Heavy Users & 115 & 4.08 & 3.19 & 0.02 \\
Disconnectors & 41 & 4.03 & & \\
Total & 518 & 4.16 & & \\
\hline
\end{tabular}

Table 7. ANOVA: Clusters and relationship satisfaction.

The results of the ANOVA suggest that there are significant differences between the clusters of Facebook users and relationship satisfaction. The Connectors are the most satisfied (4.29) while the Disconnectors are the least satisfied (4.03). Light Users (4.06) and Heavy Users (4.08) have medium relationship satisfaction comparatively. Post-hoc analysis demonstrated the difference between Connectors and Light Users was significant as $\mathrm{p}<0.05$.

Based on the above analysis as well as the findings in the first two research questions, the matrix in Table 8 classifies Facebook users based on the intensity level of Facebook usage and level of relationship satisfaction.

\begin{tabular}{|c|c|c|c|}
\hline User Type & Type of Use & Individual Characteristics & $\begin{array}{l}\text { Relationship } \\
\text { Satisfaction }\end{array}$ \\
\hline $\begin{array}{l}\text { Disconnectors } \\
(10 \%)\end{array}$ & $\begin{array}{l}\text { Have a Facebook account, but do not use it } \\
\text { for any particular reason, and have a low } \\
\text { level of intensity of use. They are connected } \\
\text { with their partners on Facebook, but their } \\
\text { partners are heavier users than them. }\end{array}$ & $\begin{array}{l}\text { More likely to be younger } \\
\text { males with a low level of } \\
\text { identification with their } \\
\text { peer group. }\end{array}$ & Lowest \\
\hline $\begin{array}{l}\text { Light Users } \\
(29 \%)\end{array}$ & $\begin{array}{l}\text { Use Facebook to connect with friends and } \\
\text { family, but without including their partner, } \\
\text { and with very light intensity of use. }\end{array}$ & $\begin{array}{l}\text { Strongly skewed towards } \\
\text { females, and older users, } \\
\text { with lower levels of peer } \\
\text { group identification. }\end{array}$ & $2^{\text {nd }}$ Lowest \\
\hline $\begin{array}{l}\text { Heavy Users } \\
(22 \%)\end{array}$ & $\begin{array}{l}\text { Having the highest level of use intensity, } \\
\text { these users connect with friends and family } \\
\text { on Facebook, but are also using it for a range } \\
\text { of other activities including gathering and } \\
\text { sharing information. They are friends with } \\
\text { their partners, but their partners are lighter } \\
\text { users. }\end{array}$ & $\begin{array}{l}\text { More likely to be males of } \\
\text { average age, with high peer } \\
\text { group identification. }\end{array}$ & $2^{\text {nd }}$ Highest \\
\hline $\begin{array}{l}\text { Connectors } \\
(39 \%)\end{array}$ & $\begin{array}{l}\text { Use Facebook primarily to connect with } \\
\text { family and friends, are friends with their } \\
\text { partner - who is also part of their peer group } \\
\text { and have a relatively high intensity of } \\
\text { Facebook usage. }\end{array}$ & $\begin{array}{l}\text { More likely to be males (of } \\
\text { any age). They also feel a } \\
\text { stronger connection to their } \\
\text { peers on Facebook. }\end{array}$ & Highest \\
\hline
\end{tabular}

Table 8. Facebook usage types ordered by relationship satisfaction (lowest to highest). 


\section{Discussion and analysis}

The first research question prompted investigation of relationship satisfaction, Facebook intensity and identification with peer groups with respect to household income and living arrangements. It was found that those living alone or with children and on a low income were less satisfied with their relationships and may rely more on social media to connect with friends and family. This echoes recent Pew Research (2014) findings, highlighting an area requiring further research and attention from support service providers. Like the findings of Denti et al. (2012), we found that Facebook usage did not seem to assist in relationships satisfaction for those on low income with children or those living alone on limited means. As such, social media may not be used as a 'remedy' to assist those who struggle financially.

The second research question explored if the way Facebook was used influenced relationship satisfaction, while controlling for household income. The results indicated that there were differences in relationship satisfaction based on the way Facebook was used. In instances where Facebook was not used to keep in touch with family and friends, higher rates of relationship dissatisfaction were found. This was particularly associated with low income households. When a partner is a heavier user of Facebook, low income respondents were more likely to be unsatisfied with their relationship. They were also less likely to be satisfied when they used Facebook to connect with organisations or for work. Excluding a partner from your group of 'friends' on Facebook was also related to lower levels of relationship satisfaction. This finding aligns with Uncertainty Reduction Theory (URT) which posits that increasing the 'amount of communication with a partner's network' will reduce uncertainty and enhance the stability of a relationship (Parks \& Adelman, 1983 p. 57).

The final research question explored whether people could be grouped based on their Facebook usage and whether these groups differed based on relationship satisfaction. The study found that people could be grouped and that relationship satisfaction did vary based on Facebook usage. Table 8 presents the results highlighting four key groups: Disconnectors (low relationship satisfaction), Light Users and Heavy Users (medium relationship satisfaction) and Connectors (high relationship satisfaction). The Disconnector group is differentiated by light levels of Facebook usage intensity and weak connections with their peer group on Facebook. Disconnectors are more likely to be younger and to have low income. Connectors are moderate Facebook users who primarily use Facebook to connect with family and friends and are more likely to feel connected to their Facebook peer group. The distinction between Connectors and Disconnectors can be framed through the lens of URT (Parks \& Adelman, 1983), in that relationship satisfaction is enhanced through the maintenance of strong connections with family and friends and a partner on Facebook.

The light and heavy users on the other hand, differed in intensity of usage and connection with peers on Facebook, but not in relationship satisfaction. While the light users tend to be older females, the heavy users are younger females. What distinguishes them from the connectors is the level of inclusion of their partner. Again, this supports URT suggesting that Facebook usage does not enhance one's relationship when partners are excluded or less involved in the social media activities.

Recent Australian and US research indicates that social media use is having a negative impact on users' relations to others (Clayton, Nagurney, et al., 2013; Clayton, Osborne, Miller, \& Oberle, 2013; Mod, 2010; Muise, Christofides, \& Desmarais, 2009; Rahaman, 2015). This is in contrast with studies that indicate that social media use can have a positive impact on users' 
relations to others (Baker \& Oswald, 2010; N B Ellison et al., 2007). This motivated our research to get a better sense of whether social media use was helpful or harmful in terms of its impact on intimate relationship satisfaction. The results uncovered, that for some users, social media use is harmful and for others it is helpful. However, it is not purely use or overuse that leads to social media being harmful to intimate relationships. Rather, our findings indicate that users can be grouped into four types and that connection with one's partner via social media plays a key role in maintaining relationship satisfaction.

\section{Theoretical and practical implications}

The findings of this research provide theoretical and practical implications. The study indicates that URT holds in the social media setting. That is, increasing the 'amount of communication with a partner's network' reduces uncertainty and enhances the stability of a relationship (Parks \& Adelman, 1983 p. 57). In addition this study contributes to the current literature which focuses on the US context, through an Australian case study, building the body of knowledge relating to social media use and its impact on intimate relationships.

One catalyst for the research was a recent finding of an Australian counselling provider that social media is increasingly contributing to negative relationship outcomes for clients (Relationships Australia, 2011). Our findings have the potential to inform counselling practice and support resource development through the identification of four usage types that experience differing levels of relationship satisfaction. Importantly, our results indicate that intensity or overuse is not as critical to relationship satisfaction as how and who you use social media with.

\section{Limitations and agenda for future research}

An online panel was used to collect the sample for this study. Online panels (especially Amazon's MTurk) have been criticised for being narrow in terms of demographics, as well as having users intentionally cheating with their answers (Smith, Roster, Golden, \& Albaum, 2016). However, other studies have found the opposite, suggesting that online panels produce better results than face-to-face research approaches (Casler, Bickel, \& Hackett, 2013; Hauser \& Schwarz, 2016). In our study, a reputable Australian market research company (the Online Research Unit, http://www.theoru.com/) was used. Further, the sample was purposely selected to include a proportion of low-income participants. Further research may wish to collect a sample using a different approach and compare to what extent the results varies.

This research project relied on 'traditional' methods, using a 'small data' approach. The approach in itself has its limitations when the topic investigated relates to usage of a service that more than nine out of ten Australians use in some form. To extend the current study, a Big Data approach could for example use an API to scrape social media data and then use the meta data together with a text analysis software such as Linguistic Inquiry and Word Count (LIWC) (Pennebaker, Booth, Boyd, \& Francis, 2015; Pennebaker, Boyd, Jordan, \& Blackburn, 2015) to investigate what users talk about, who they talk with and how they express themselves linguistically. Such a study could provide further insight into for example different emotional tones used as well as social status. Thus, it would be possible to map different types of interactions on social media. However, a big data approach would have difficulties in capturing the level of satisfaction with user's offline intimate relationships. 
These findings provide a snapshot of the impact that Facebook usage has on relationship satisfaction in the Australian context. The findings relating to low income groups are new in this context, augmenting recent findings from the United States. Future research should further examine the impact that social media use has on low income groups.

\section{Conclusion}

This study examined the impact that Facebook usage has on relationship satisfaction with a specific focus on exploring the impact on low income groups. Findings indicate that relationship satisfaction varies based on the kind of Facebook usage, not just the frequency and duration of Facebook usage, as has been highlighted in previous studies. Four key groups of Facebook users were developed: Disconnectors, Light Users, Heavy Users and Connectors. Connectors had the highest level of relationship satisfaction and were exemplified through using Facebook to connect with family and friends, strong identification with their peer group on Facebook and including their partner in their group of Facebook 'friends'. These findings echo URT which posits that maintaining close ties with a partner's family and friends can lead to enhanced relationship outcomes.

The literature indicates that social media use can have a helpful or harmful impact on intimate relationships. Our findings extend this body of knowledge, showing that how you use social media and who you use social media to connect with plays a key role in relationship satisfaction.

\section{References}

AAML. (2010). Big Surge in Social Networking Evidence Says Survey of Nation's Top Divorce Lawyers. Retrieved from http://aaml.org/about-the-academy/press/press-releases/ediscovery/big-surge-social-networking-evidence-says-survey-

ABS. (2016). 8146.0 - Household Use of Information Technology, Australia, 2014-15. Retrieved from http://www.abs.gov.au/ausstats/abs@.nsf/mf/8146.0

APS. (2015). Stress \& wellbeing: How Australians are coping with life. Retrieved from http://www.psychology.org.au/Assets/Files/PW15-SR.pdf

Baker, L. R., \& Oswald, D. L. (2010). Shyness and online social networking services. Journal of Social and Personal Relationships, 27(7), 873-889. doi:10.1177/0265407510375261

Berger, C. R. (1986). Uncertain Outcome Values in Predicted Relationships Uncertainty Reduction Theory Then and Now. Human Communication Research, 13(1), 34-38. doi:10.1111/j.1468-2958.1986.tb00093.x

Berger, C. R., \& Calabrese, R. J. (1975). Some Explorations in Initial Interaction and Beyond: Toward a Developmental Theory of Interpersonal Communication. Human Communication Research, 1(2), 99-112. doi:10.1111/j.1468-2958.1975.tb00258.x

Boyd, D. M., \& Ellison, N. B. (2007). Social Network Sites: Definition, History, and Scholarship. Journal of Computer-Mediated Communication, 13(1), 210-230. doi:10.1111/j.10836101.2007.00393.x

Caers, R., De Feyter, T., De Couck, M., Stough, T., Vigna, C., \& Du Bois, C. (2013). Facebook: A literature review. New Media \& Society, 15(6), 982-1002. doi:10.1177/1461444813488061 
Carlson, B., Farrelly, T., Frazer, R., \& Borthwick, F. (2015). Mediating Tragedy: Facebook, Aboriginal Peoples and Suicide. Australasian Journal of Information Systems, 19. doi:http://dx.doi.org/10.3127/ajis.v19i0.1174

Casler, K., Bickel, L., \& Hackett, E. (2013). Separate but equal? A comparison of participants and data gathered via Amazon's MTurk, social media, and face-to-face behavioral testing. Computers in Human Behavior, 29(6), 2156-2160. doi:https://doi.org/10.1016/j.chb.2013.05.009

Chou, H.-T. G., \& Edge, N. (2012). 'They Are Happier and Having Better Lives than I Am': The Impact of Using Facebook on Perceptions of Others' Lives. CyberPsychology, Behavior $\mathcal{E}$ Social Networking, 15(2), 117-121. doi:10.1089/cyber.2011.0324

Clayton, R. B., Nagurney, A., \& Smith, J. R. (2013). Cheating, Breakup, and Divorce: Is Facebook Use to Blame? CyberPsychology, Behavior \& Social Networking, 16(10), 717-720. doi:10.1089/cyber.2012.0424

Clayton, R. B., Osborne, R. E., Miller, B. K., \& Oberle, C. D. (2013). Loneliness, anxiousness, and substance use as predictors of Facebook use. Computers in Human Behavior, 29(3), 687-693. doi:http://dx.doi.org/10.1016/j.chb.2012.12.002

Collins, L. M., \& Lanza, S. T. (2010). Latent Class and Latent Transition Analysis: With Applications in the Social, Behavioral, and Health Sciences. NJ, USA: Wiley.

Constantinides, E. (2014). Foundations of Social Media Marketing. Procedia - Social and Behavioral Sciences, 148, 40-57. doi:10.1016/j.sbspro.2014.07.016

Dang-Pham, D., Pittayachawan, S., \& Nkhoma, M. (2015). Demystifying online personas of Vietnamese young adults on Facebook: A Q-methodology approach. Australasian Journal of Information Systems, 19. doi:http://dx.doi.org/10.3127/ajis.v19i0.1204

Denti, E., Barbopoulos, I., Nilsson, I., Holmberg, L., Thulin, M., Wendeblad, M., . . Davidsson, E. (2012). Sweden's largest Facebook study. Retrieved from http://hdl.handle.net/2077/28893

DHS. (2015). Low Income Supplement. Retrieved from http://www.humanservices.gov.au/customer/services/centrelink/low-incomesupplement

Ellison, N., Steinfield, C., \& Lampe, C. (2006, 19-23 June). Spatially Bounded Online Social Networks and Social Capital: The Role of Facebook. Paper presented at the Annual Conference of the International Communication Association, Dresden, Germany.

Ellison, N. B., Steinfield, C., \& Lampe, C. (2007). The Benefits of Facebook "Friends:" Social Capital and College Students' Use of Online Social Network Sites. Journal of ComputerMediated Communication, 12(4), 1143-1168. doi:10.1111/j.1083-6101.2007.00367.x

Ellison, N. B., Steinfield, C., \& Lampe, C. (2011). Connection strategies: Social capital implications of Facebook-enabled communication practices. New Media \& Society, 13(6), 873-892. doi:10.1177/1461444810385389

Erdley, C. A., Nangle, D. W., \& Burns, A. M. (2011). Friends. In S. Goldstein \& J. A. Naglieri (Eds.), Encyclopedia of Child Behavior and Development. New York: Springer. 
Fox, J., \& Warber, K. M. (2014). Social Networking Sites in Romantic Relationships: Attachment, Uncertainty, and Partner Surveillance on Facebook. CyberPsychology, Behavior \& Social Networking, 17(1), 3-7. doi:10.1089/cyber.2012.0667

Gilbert, E., \& Karahalios, K. (2009). Predicting tie strength with social media. Paper presented at the CHI '09 The SIGCHI Conference on Human Factors in Computing Systems, Boston, MA, USA.

Granovetter, M. S. (1973). The Strength of Weak Ties. American Journal of Sociology, 78(6), 13601380. doi:doi:10.1086/225469

Hacker, J., Wickramasinghe, N., \& Durst, C. (2017). Can Health 2.0 Address Critical Healthcare Challenges? Insights from the Case of How Online Social Networks Can Assist in Combatting the Obesity Epidemic. Australasian Journal of Information Systems, 21. doi:http://dx.doi.org/10.3127/ajis.v21i0.1357

Hamit, S. (2011). Peer Group. In S. Goldstein \& J. A. Naglieri (Eds.), Encyclopedia of Child Behavior and Development. New York: Springer.

Hauser, D. J., \& Schwarz, N. (2016). Attentive Turkers: MTurk participants perform better on online attention checks than do subject pool participants. Behavior Research Methods, 48(1), 400-407. doi:10.3758/s13428-015-0578-z

Hendrick, S. S. (1988). A Generic Measure of Relationship Satisfaction. Journal of Marriage and Family, 50(1), 93-98. doi:10.2307/352430

Hendrick, S. S., Dicke, A., \& Hendrick, C. (1998). The Relationship Assessment Scale. Journal of Social and Personal Relationships, 15(1), 137-142. doi:10.1177/0265407598151009

Hu, T., Kettinger, W. J., \& Poston, R. S. (2015). The effect of online social value on satisfaction and continued use of social media. European Journal of Information Systems, 24(4), 391-410. doi:10.1057/ejis.2014.22

Kietzmann, J. H., Hermkens, K., McCarthy, I. P., \& Silvestre, B. S. (2011). Social media? Get serious! Understanding the functional building blocks of social media. Business Horizons, 54(3), 241-251. doi:10.1016/j.bushor.2011.01.005

Lambert, A. (2016). Intimacy and social capital on Facebook: Beyond the psychological perspective. New Media $\mathcal{E}$ Society, 18(11), 2559-2575. doi:doi:10.1177/1461444815588902

Maier, C., Laumer, S., Eckhardt, A., \& Weitzel, T. (2015). Giving too much social support: social overload on social networking sites. European Journal of Information Systems, 24(5), 447464. doi:10.1057/ejis.2014.3

Masyn, K. (2013). Latent class analysis and finite mixture modeling. In T. D. Little (Ed.), The Oxford handbook of quantitative methods in psychology (Vol. 2, pp. 551-611).

McCutcheon, A. L. (2002). Basic concepts and procedures in single-and multiple-group latent class analysis. In J. A. Hagenaars \& A. L. McCutcheon (Eds.), Applied latent class analysis (pp. 56-88).

McDaniel, B. T., Drouin, M., \& Cravens, J. D. (2017). Do you have anything to hide? Infidelityrelated behaviors on social media sites and marital satisfaction. Computers in Human Behavior, 66, 88-95. 
Mod, G. B. B. A. (2010). Reading romance: the impact Facebook rituals can have on a romantic relationship. Journal of Comparative Research in Anthropology and Sociology, 1(2), 61-77.

Muise, A., Christofides, E., \& Desmarais, S. (2009). More Information than You Ever Wanted: Does Facebook Bring Out the Green-Eyed Monster of Jealousy? CyberPsychology, Behavior $\mathcal{E}$ Social Networking, 12(4), 441-444. doi:10.1089/cpb.2008.0263

Papp, L. M., Danielewicz, J., \& Cayemberg, C. (2012). 'Are We Facebook Official?' Implications of Dating Partners' Facebook Use and Profiles for Intimate Relationship Satisfaction. CyberPsychology, Behavior \& Social Networking, 15(2), 85-90. doi:10.1089/cyber.2011.0291

Parks, M. R., \& Adelman, M. B. (1983). Communication Networks and the Development of Romantic Relationships: An Expansion of Uncertainty Reduction Theory. Human Communication Research, 10(1), 55-79. doi:10.1111/j.1468-2958.1983.tb00004.x

Pennebaker, J. W., Booth, R. J., Boyd, R. L., \& Francis, M. E. (2015). Linguistic Inquiry and Word Count: LIWC2015. Austin, TX: Pennebaker Conglomerates (www.LIWC.net).

Pennebaker, J. W., Boyd, R. L., Jordan, K., \& Blackburn, K. (2015). The development and psychometric properties of LIWC2015. Austin, TX: University of Texas at Austin.

Pew Research Center. (2014). Couples, the Internet, and Social Media. Retrieved from http://www.pewinternet.org/files/2014/02/PIP_Couples_and_Technology-

FIN_021114.pdf

Pew Research Center. (2016). Social Networking Fact Sheet. Retrieved from http://www.pewinternet.org/fact-sheets/social-networking-fact-sheet/

Rahaman, H. M. S. (2015). Romantic Relationship Length and its Perceived Quality: Mediating Role of Facebook-Related Conflict. Europe's Journal of Psychology, 11(3), 395-405. doi:10.5964/ejop.v11i3.932

Relationships Australia. (2011). Relationships Indicators Survey 2011. Retrieved from http://www.relationshipsvictoria.com.au/assets/PDFs/indicatorsreportfinal2011.pdf

Relationships Australia Victoria. (2015). Social media use impacts families and relationships. Retrieved from https://www.relationships.org.au/what-we-do/research/onlinesurvey/february-2015-the-internet-and-relationships

Sensis. (2016). Sensis Social Media Report 2016: How Australian people and businesses are using social media. Retrieved from https://www.sensis.com.au/asset/PDFdirectory/Sensis_Social_Media_Report_2016.PDF

Sensis. (2017). Sensis Social Media Report 2017. Retrieved from https://www.sensis.com.au/asset/PDFdirectory/Sensis-Social-Media-Report-2017.pdf

Smith, S. M., Roster, C. A., Golden, L. L., \& Albaum, G. S. (2016). A multi-group analysis of online survey respondent data quality: Comparing a regular USA consumer panel to MTurk samples. Journal of Business Research, 69(8), 3139-3148. doi:https://doi.org/10.1016/j.jbusres.2015.12.002

Song, H., Zmyslinski-Seelig, A., Kim, J., Drent, A., Victor, A., Omori, K., \& Allen, M. (2014). Does Facebook make you lonely?: A meta analysis. Computers in Human Behavior, 36, 446452. doi:http://dx.doi.org/10.1016/j.chb.2014.04.011 
Stewart, D., \& Klein, S. (2016). The use of theory in research. International Journal of Clinical Pharmacy, 38, 615-619.

Tokunaga, R. S. (2010). Social networking site or social surveillance site? Understanding the use of interpersonal electronic surveillance in romantic relationships. Computers in Human Behavior, 27, 705-713.

Tokunaga, R. S. (2011). Friend Me or You'll Strain Us: Understanding Negative Events That Occur over Social Networking Sites. CyberPsychology, Behavior \& Social Networking, 14(7/8), 425-432. doi:10.1089/cyber.2010.0140

Turel, O. (2015). Quitting the use of a habituated hedonic information system: a theoretical model and empirical examination of Facebook users. European Journal of Information Systems, 24(4), 431-446. doi:10.1057/ejis.2014.19

Turel, O., \& Serenko, A. (2012). The benefits and dangers of enjoyment with social networking websites. European Journal of Information Systems, 21(5), 512-528.

Tuten, T. L., \& Solomon, M. R. (2015). Social Media Marketing (2 ed.). Thousand Oaks, CA: SAGE.

Valenzuela, S., Halpern, D., \& Katz, J. E. (2014). Social network sites, marriage well-being and divorce: Survey and state-level evidence from the United States. Computers in Human Behavior, 36, 94-101.

Wang, X., Yu, C., \& Wei, Y. (2012). Social Media Peer Communication and Impacts on Purchase Intentions: A Consumer Socialization Framework. Journal of Interactive Marketing, 26, 198-208.

Wedel, M., \& Kamakura, W. (2000). Market segmentation: Conceptual and methodological foundations. NY, USA: Springer Science \& Business Media. 


\section{Appendix one - Survey Items}

Ellison et al.'s (2007) Facebook intensity scale was adapted for use in the study. Unless provided, response categories ranged from $1=$ strongly disagree to $5=$ strongly agree:

o About how many total Facebook friends do you have? $(0-10=1,11-50=2,51-200=3$, 201$400=4,401-=5$ )

o In the past week, on average, approximately how many minutes per day have you spent on Facebook? $(0-10=1,11-30=2,31-60=3,61-120=4$. $121-=5)$

o Facebook is part of my everyday activity

o I am proud to tell people I'm on Facebook

o Facebook has become part of my daily routine

o I feel out of touch when I haven't logged onto Facebook for a while

o I feel I am part of the Facebook community

o I would be sorry if Facebook shut down

Hendrick's (1988) scale was used to measure relationship satisfaction. Categories ranged from $1=$ low, $3=$ =neutral to $5=$ high.

o How well does your partner meet your needs?

o In general, how satisfied are you with your relationship?

o How good is your relationship compared to most?

o How often do you wish you hadn't gotten into this relationship?

o To what extent has your relationship met your original expectations?

o How much do you love your partner?

o How many problems are there in your relationship?

Wang et al.'s (2012 p. 203) identification with the peer group scale was adapted for use:

o I am very attached to the peer group on Facebook.

o $\quad$ My peers on Facebook and I share the same objectives.

o The friendships I have with my peers on Facebook mean a lot to me.

o If my peers on Facebook planned something, I'd think of it as something "we" would do rather than "they" would do.

o I see myself as a part of the peer group on Facebook.

Items used to measure Facebook Usage based on (Sensis, 2016):

o Please select the options that best indicate why you use Facebook (more than one allowed):

o To keep in touch with family and friends

o I use it for work

o I use it to connect with organisations

o I use it to gather information

o I use it to share information

o I use it to meet new people

o $\quad$ My partner uses Facebook: (more than me, less than me, about the same amount)

o Is your partner part of a group of friends that you most frequently interact with (your peer group) on Facebook? Yes/No 
Copyright: (C) 2018 Whiteside, Aleti, Pallant \& Zeleznikow. This is an open-access article distributed under the terms of the Creative Commons Attribution-NonCommercial 3.0 Australia License, which permits non-commercial use, distribution, and reproduction in any medium, provided the original author and AJIS are credited.

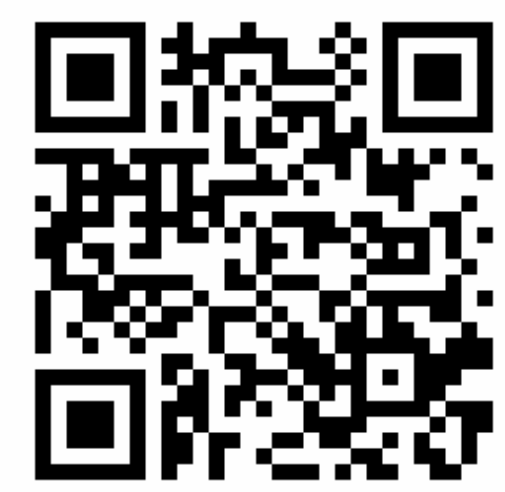

